\title{
Black snub-nosed monkeys in China
}

\author{
Yang De-hua
}

\begin{abstract}
The black snub-nosed monkey Rhinopithecus bieti is facing extinction. Although some work has been done on the other Chinese snub-nosed monkeys, $R$. roxellanae and $R$. brelichi, very little is known about $R$. bieti. The author describes the results of the first detailed ecological survey of this species.
\end{abstract}

The rare black snub-nosed monkey is little known to the outside world, and even within China few people have seen one. This is not surprising for these monkeys live at high altitudes in dense forests on steep slopes, conditions that make surveys difficult. Moreover, this species has never been exhibited in any zoo in the world; nor is there any report on its breeding, and little is known of its ecology. In March 1987, the Kunming Institute of Zoology captured four monkeys; only one is now alive and is being kept at the Institute for breeding.

Black snub-nosed monkeys first became known to science in 1871 when French naturalists learnt about them from Chinese people, but they did not see them until 1890; later they succeeded in procuring seven specimens in Yunnan (Allen, 1938). They were identified as Rhinopithecus bieti in 1879 by Milne-Edwards. The next scientific reports of the species came in 1962 when Chinese zoologists collected eight skins in north-west Yunnan (Pen et al., 1962). In 1979, zoologists from the Kunming Institute of Zoology, Academia Sinica, obtained a further four skins from north-west Yunnan ( $\mathrm{Li}$ et al., 1981).

Between April and July 1981 Dr Mu Wenwei of the Institute of Medical Biology and I conducted a survey of $R$. bieti, and obtained the first detailed information on its population, distribution, ecology and behaviour (Yang, 1981).

Black snub-nosed monkeys in China
The study was sponsored by the Kunming Institute of Zoology, Academia Sinica and the Institute of Medical Biology, Chinese Academy of Medical Science. As a follow-up to this work, the Chinese Academy of Sciences sponsored the Kunming Institute of Zoology to do more comprehensive research on captive breeding and genetics.

The distribution of the black snub-nosed monkey is given in Figure 1, which also shows the position of our study site on the east side of Baima-snowed Mountain, which is part of the Hengduan Shan range, in Deqên county. A good population of snub-nosed monkeys was known to exist there (Li et al, 1981). The steep mountainous terrain is covered in dense forest of spruce, silver fir, pine, oak and poplar.

Since the monkeys travel over large areas in steep terrain, it is impossible for observers to keep up with them all the time. For a fuller account of the monkey's ecology we, therefore, supplemented our own observations with those of experienced hunters who had followed and captured the monkeys.

We found that two groups of black snub-nosed monkey lived on the east side of Baima-snowed Mountain. One group consisted of 40-50 individuals, the other of 120 animals. Their ranging patterns are shown in Figure 2. The 


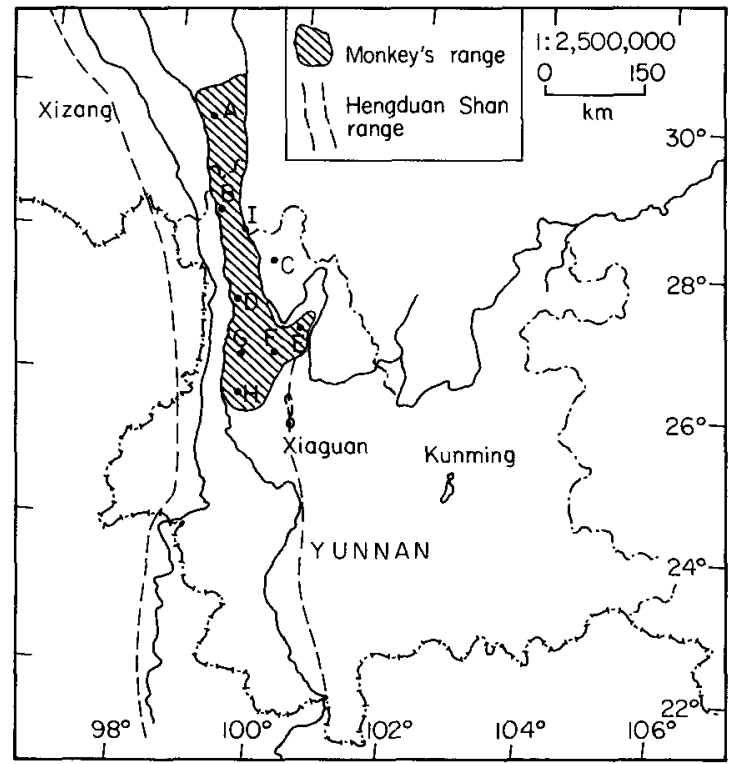

Figure 1. The distribution of the black snub-nosed monkey showing locations of known populations: (A) Markam,

(B) Deqen, (C) Zhongdian, (D) Weixi, (E) Lijiang,

(F) Jianchuan, (G) Lanping, (H) Yunlong, (I) Study site, Baima-snowed Mountain.

main summer foods are the young shoots of coniferous trees. During the survey we met some native hunters who had captured a young monkey, and we offered it various natural foods as an experiment. The experimental results are given in Table 1. From observations made when we were able to follow the monkeys for a complete day, we established that they feed mainly in the early morning and late afternoon, and sleep for two hours around midday. They travel and feed both in trees and on the ground.

According to the local people there were more than 800 monkeys on the east side of Baimasnowed Mountain in the $1960 \mathrm{~s}$. At that time no one hunted them because there was plenty of wildlife and, in addition, local people regarded them as being closely related to humans. Later this tradition broke down and young people began to poach them. Improved hunting equipment, and its greater availability, have made poaching much easier, and it has been encouraged by a local dealer purchasing monkey bones and skins. The local people use the bones, brains and other parts of the monkeys for medicinal purposes. According to the data we 42 collected from local hunters, 32 were killed in 1978, 36 in 1979, 25 in 1980, and 27 in early 1981 , on the east side of Baima-snowed Mountain alone. Although the monkeys are legally protected the local government is not able to enforce the law effectively.

We propose three conservation measures: (i) a complete survey of the remaining habitat should be made to determine total population size and distribution within the species's range; (ii) effective methods should be devised to prevent further killing of the monkeys; (iii) one or two nature reserves, or other protected areas, should be established immediately to protect the last remaining populations of black snub-nosed monkeys.

\section{Acknowledgments}

We thank the Kunming Institute of Zoology and the Institute of Medical Biology for sponsoring the work described

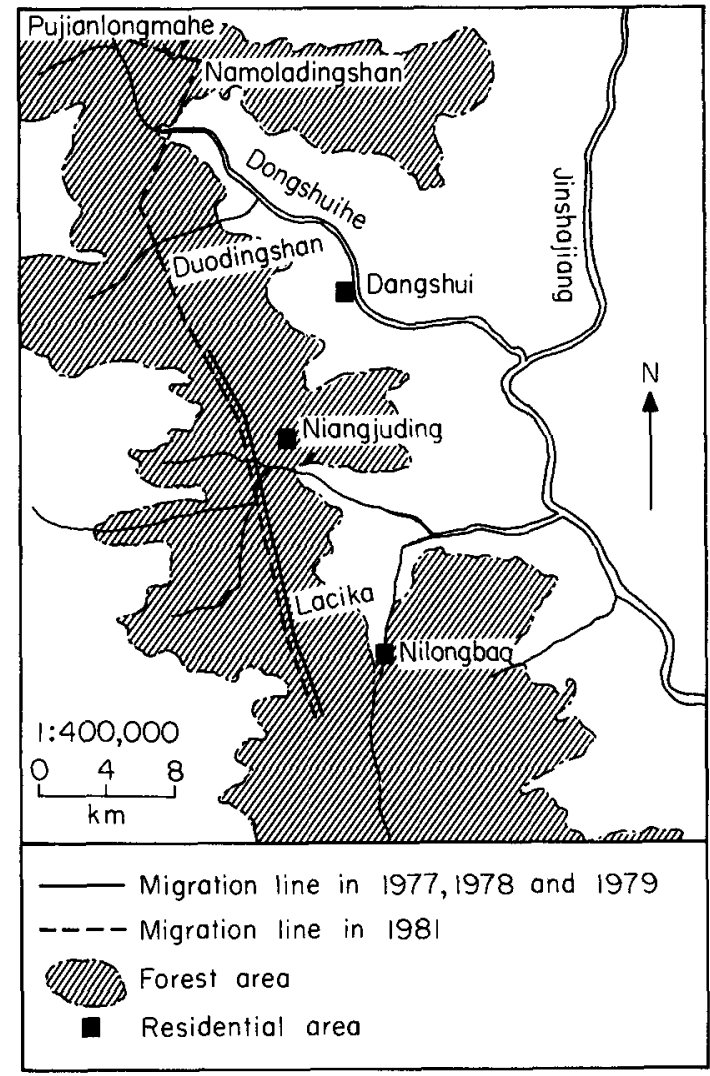

Figure 2. Ranging patterns of the black snub-nosed monkeys on the east side of Baima-snowed Mountain.

Oryx Vol 22 No 1, January 1988 
Table 1. Record of the experimental feeding of a young monkey captured during the course of the study

\begin{tabular}{|c|c|c|c|}
\hline Date & Food offered & Food eaten & Part eaten \\
\hline 22.5 .81 & $\begin{array}{l}\text { Abies georgie, A. ferreana, Pinus armandi, } \\
P . \text { yunnanensis, Populus davidiana, } P \text {, yunnanensis, } \\
\text { Quercus pannosa, Usea longissima }\end{array}$ & Usea longissima & Whole \\
\hline 23.5 .81 & $\begin{array}{l}\text { Abies georgei, A. ferreana, Pinus armandi, } \\
P . \text { yunnanensis, Populus davidiana, } P \text {. yunnanensis, } \\
\text { Quercus pannosa }\end{array}$ & $\begin{array}{l}\text { A. georgei, A. ferreana, } \\
\text { P. armandi }\end{array}$ & Young and old needles \\
\hline 25.5 .81 & $\begin{array}{l}\text { Pinus yunnanensis, Quercus pannosa, Populus } \\
\text { davidiana, } P \text {. yunnanensis }\end{array}$ & Pinus yunnanensis & Young and old needles \\
\hline 26.5 .81 & Populus davidiana, $P$. yunnanensis, Quercus pannosa & Quercus pannosa & Young leaves \\
\hline 27.5 .81 & Populus davidiana, $P$. yunnanensis & Nothing & - \\
\hline
\end{tabular}

in this paper. Mr Yang Hu of the Kunming Institute of Zoology, Academia Sinica, encouraged, helped and advised during my collection and preparation of the data; he also commented on this paper. I express my sincere thanks to him.

\section{References}

Allen, G.M. 1938. The mammals of China and Mongolia.

Voi. I. Am. Mus. Nat. Hist., New York.

Li, Z.X., Ma, S.L., Hua, C.H. and Wang, Y.X. 1981. The distribution and habit of Yunnan snub-nosed monkey. Zool. Res. 2(1), 9-16.
Pen, H.S., Kao, Y.T., Lu, C.K., Feng, T.C. and Chen, C.H. 1962. Report on Mammals from Southwestern Szechwan and Northwestern Yunnan. Acta Zool. Sinica, 14 (suppl.), 114-115.

Yang, D.H. 1981. The survey on R. bieti in Baima-snowed mountain. Da Ziren (Nature) 4, 31-32. Beijing.

Dr Yang De-hua, c/o Mr Yang Hu, Kunming Institute of Zoology, Academia Sinica, Kunming, Yunnan, People's Republic of China. 